\title{
Abraham Horwitz Barak
}

\author{
Enrique Laval $R$.
}

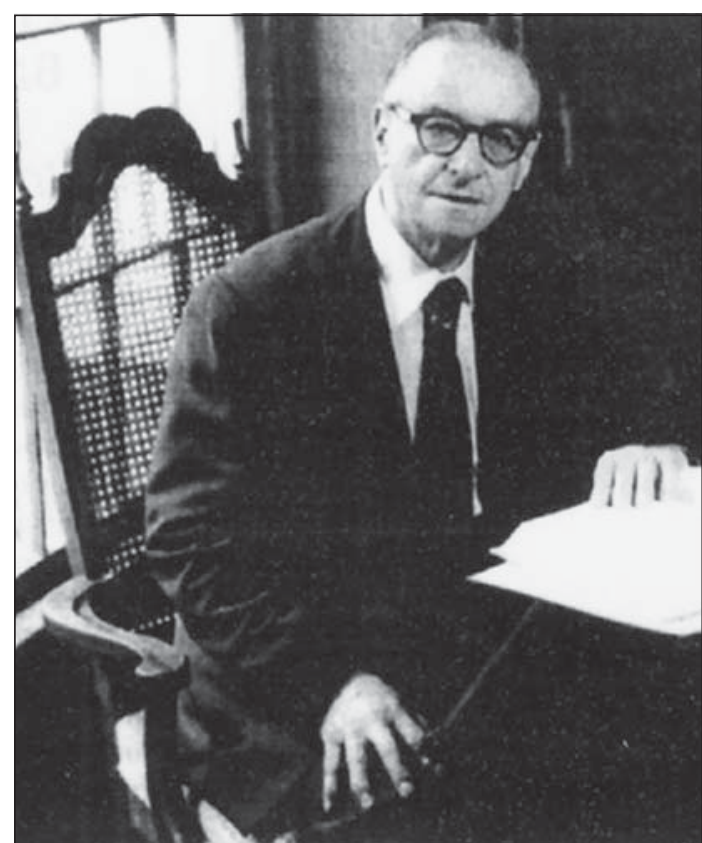

A su llegada a Nueva York, si doña Catalina Barak, esposa de don Isidoro Horwitz, no hubiera padecido de una conjuntivitis bacteriana, que las autoridades sanitarias supusieron que se trataba de tracoma, enfermedad infecto-contagiosa que no permitía ingresar a los Estados Unidos, su hijo menor Abraham, habría sido norteamericano y no chileno. Nuestro país debería enorgullecerse de contar, desde el 25 de diciembre de 1910 , fecha de su nacimiento, con el que llegaría a ser un gran especialista de la Medicina, en la Clínica de las Enfermedades Infecciosas y de la Salud Pública. También dos de los hermanos de Abraham, José e Isaac, fueron médicos psiquiatras. El Instituto Nacional y luego la Universidad de Chile, los acogieron en la educación secundaria y enseñanza de la Medicina, respectivamente ${ }^{1,2}$.

Atrás habían quedado los recuerdos de su imaginación desde la Bielorusia hacia las tierras americanas y en Chile Abraham Horwitz iba a iniciar su peregrinaje médico, hacia importantes y destacados cargos, en su quehacer profesional.

El doctor Abraham Horwitz recibió el título de médico en 1936, adquiriendo los conocimientos fundamentales de la patología infecciosa, como ayudante de la Cátedra de Bacteriología del Profesor Hugo Vaccaro.

Desde 1942 a septiembre de 1943, becado por la Fundación Rockefeller, fue médico residente en el Hospital de Enfermedades Infecciosas Herman Kiefer de Detroit, Michigan, especializándose en Enfermedades Infecciosas y obteniendo el título de "Master of Public Health" de la Universidad de John Hopkins, el año $1944^{2}$.
Junto con los doctores Roque Kraljeviæ y José Perroni, formaron el grupo de los "tres mosqueteros" y como en la obra de Alejandro Dumas, "no serían tres sino cuatro". Este "cuarto mosquetero", el Dr. D’Artagnan, fue el Profesor Lucio Córdova, quien "realzando el enlace íntimo entre la patología individual y la social, amplía sobremanera el campo de estudio de las enfermedades infecciosas, puesto que el médico no sólo debe dominar la clínica, bacteriología, terapéutica y la inmunología con sus métodos de profilaxis individual y la experimentación, además de la importancia del medio ambiente en que el enfermo ha adquirido su infección, etc". Por todo esto la Junta Central de Beneficencia y Asistencia Social de la cual formó parte el Profesor Lucio Córdova, desde fines de 1938 hasta abril de 1942, aprobó la indicación formulada por él, "para la construcción en Santiago de un Pabellón Modelo para la hospitalización de los enfermos infecciosos, destinado también a estudiar científicamente los múltiples problemas, individuales y colectivos, que comportan las enfermedades infecto-contagiosas". Es entonces cuando emergen los "tres mosqueteros" ya mencionados, que colaborarán en forma entusiasta a la realización de los propósitos enunciados ${ }^{3}$.

Como lo relata el Profesor Roque Kraljeviæ"la amistad con el doctor Horwitz, se inició en el año 1933, en la Cátedra de Bacteriología del Profesor Hugo Vaccaro, donde se desempeñaban como ayudantes, además de los doctores Julio Meneghello y José Perroni”.

Los contactos diarios prosiguieron luego, entre 1936 y 1939, al ingresar los doctores Horwitz, Kraljeviæ y Perroni, al Servicio de Medicina e Infecciosos del Hospital Ramón Barros Luco, dirigido por el Profesor Lucio Córdova. El doctor Meneghello comenzaba en esa época su brillante carrera en el campo de la Pediatría. Este pequeño grupo, cuyo líder era el doctor Abraham Horwitz, inició una serie de trabajos de investigación clínica y de laboratorio dirigidos a un mejor conocimiento de las enfermedades infecciosas, a nivel regional y nacional.

Estas investigaciones y sobre todo, un importante estudio de las características clínicas y epidemiológicas de la epidemia de infección meningocóccica ocurrida 
en el país entre 1941 y 1944, le sirvió de tesis al doctor Horwitz para obtener el título de Profesor Extraordinario de Enfermedades Infecciosas de la Facultad de Medicina de la Universidad de Chile, en el año 1942.

De regreso a su país, fue designado director de la Escuela de Salud Pública, continuando con sus actividades docentes en las Escuelas de Medicina de las Universidades de Chile y Católica.

Entre 1950 y 1953, realizó diversas labores en la Oficina Sanitaria Panamericana (Oficina Regional para las Américas de la Organización Mundial de la Salud) tanto en Washington D.C., como en otros países². En seguida, vuelve a Chile. En 1952, se logró la aprobación de la ley 10.383, que dio origen al Servicio Nacional de Salud. El doctor Jorge Jiménez de la Jara recuerda: "ahi estuvo nuevamente el doctor Abraham Horwitz, convocado por sus pares y ganando por concurso de antecedentes el puesto de Sub-Director Normativo, dispuesto a cumplir la ineludible tarea de organizar esta nueva institución”, permaneciendo en dicho cargo durante seis años.

Jiménez de la Jara agrega que "hacia 1957, el Servicio Nacional de Salud iniciaba ya su marcha hacia el destino de ser una institución sólida y eficaz en la medicina social chilena y sus impulsores iniciales empezaron a mirar a otros destinos. Abraham Horwitz a los 47 años tenía el suyo en la Oficina Panamericana Sanitaria (OPS). El Gobierno de Chile postuló su mejor hombre para dirigir la OPS y en votación mayoritaria, el doctor Horwitz fue elegido su Director en 1958, siendo reelecto por períodos consecutivos de 4 años, el último de los cuales terminó el 31 de enero de $1975^{1}$. En esta organización su labor se caracterizó por la integración de la salud con el desarrollo económico y fue muy exitoso en la consecución de inversiones en los servicios de salud y de saneamiento en los países de las Américas ${ }^{4}$.

Para Abraham Horwitz el tema central de su periodo en la OPS fue la relación entre Salud y Desarrollo, manifestándolo así en 1960: "la salud no constituye un fin en sí misma, no vivimos únicamente para ser sanos, una de las mayores empresas de nuestro tiempo es la preservación de las culturas con el debido respeto de las tradiciones y la forma de vida de todos los pueblos y con plena confianza en los valores de la ética humanística".

Al analizar los temas de salud y proponer estrategias sanitarias, Horwitz tuvo dos preocupaciones básicas: saneamiento ambiental y nutrición. "El sistema de agua debería ser autofinanciado en las ciudades, lo que involucra una organización racional, una administración eficiente y un régimen de tarifas, proporcional al consumo y calculado sobre el costo real de los servicios". La nutrición fue el otro asunto que ocupó un espacio en la mente y en la acción de Horwitz, incluso hasta sus últimos años de actividad. En 1959 escribía: "en relación a la alimentación, el problema no es la cantidad, sino la calidad de ésta. La región se caracteriza por una baja ingesta de proteina de origen animal, lo que afecta especialmente a los niños, debido a la grave desnutrición no les permite resistir las agresiones del ambiente y trae la consiguiente alta proporción de muertes"1.

El doctor Abraham Horwitz fue nombrado Director Emérito de la Organización Panamericana de la Salud por resolución de los Ministros de Salud de los Países Miembros de la OPS, durante la XIX Conferencia Sanitaria Panamericana. Al momento de retirarse de la OPS, en 1975, el personal creó el Premio Abraham Horwitz para la Salud Interamericana, que la Fundación Panamericana de la Salud y Educación otorga cada año a una persona o grupo de personas por su realización científica o pedagógica en cualquier campo de la salud. En 1995 lo recibió un chileno: el doctor Jorge Mardones Restat, profesor de Farmacología de la Universidad de Chile y Ministro del Presidente Gabriel González Videla ${ }^{2,5}$.

Tanto la actividad del Profesor Horwitz en el campo universitario, de la Salud Pública nacional e internacional, así como los galardones y distinciones tan merecidos, llenarían varias páginas. Sólo mencionaré algunos: su elección por vida a la Sociedad de "Scholars" de la Universidad de Johns Hopkins; el Premio "Ramón Melgarejo" de la Sociedad Médica de Santiago en 1945 y 1949, por sus estudios sobre viruela y hepatitis. En 1992, la Universidad de Johns Hopkins le otorgó el título de Doctor Honoris Causa. Ese mismo año fue nombrado Miembro por Vida de la Asociación de Salud Pública del Caribe. Fue condecorado por los Gobiernos de Bolivia, Brasil, Colombia, Chile, Ecuador, Haití, México, Panamá, Paraguay y Perú. Entre 1958 y 1959 fue Vicepresidente de la Asociación Americana de Salud Pública y de 1978 a 1986, Presidente de Programas Internacionales de Nutrición de la Academia de Ciencias de los Estados Unidos. Miembro Honorario de nuestra Sociedad Chilena de Infectología, así como de las Facultades de Medicina de las Universidades de Chile y Pontificia Universidad Católica. En 1972, la Academia de Medicina del Instituto de Chile, lo nombró Académico Honorario. En sus últimos años actuó como Asesor Especial del Director de la OPS, en algunos programas de salud de importancia para las Américas, Presidente del Subcomité de Nutrición del Comité Administrativo de Coordinación de las Naciones Unidas y Presidente de la Fundación Panamericana de la Salud y Educación (PAHEF).

La Universidad de Chile, lo distinguió con las honrosas designaciones de "Profesor Emérito y Doctor Honoris Causa", por su brillante carrera docente como 
Profesor de Enfermedades Infecciosas, en la Escuela de Salubridad, Profesor de Higiene y Medicina Preventiva de la Escuela de Medicina y además como Director de la Escuela de Salubridad.

El Profesor Roque Kraljeviæ-lo llama su "Amigo de Verdad"- destaca "que desde joven mostró un carácter afable y un espíritu jovial, alegre, siempre dispuesto a celebrar un buen chiste o una broma inocente ajena. Era tierno y emotivo con quienes dispensaba su afecto. Tenía comprensión y bondad para perdonar los errores involuntarios ajenos. Fue generoso con sus ideas y conocimientos para servir mejor a los demás. Estaba dotado de una clara inteligencia, con una notable capacidad creadora y una fina perspicacia para orientar la búsqueda de la verdad"2.

Finalmente, deseo señalar la profunda amistad y mutua admiración entre el Profesor Abraham Horwitz y el Profesor Hernán Alessandri, que se ve también claramente cuando aquel destaca la inseparable ligazón entre la medicina clínica y la salud pública, en la cual siempre creyó: "la medicina individual y colectiva son elementos fundamentales en el ataque concertado que procede al enfrentar las "enfermedades sociales", comprendiendo con esta expresión todas aquellas que limitan el bienestar. Debiera terminar el viejo conflicto entre la Medicina Preventiva y la Curativa, entre Hygeia y Esculapio".

Sin duda, don Abraham Horwitz Barak ha sido una de las figuras más brillantes de la medicina chilena durante el siglo recién pasado.

Falleció después de una larga y penosa enfermedad, en la ciudad de Washington D.C., el 10 de julio de 2000. Sus restos fueron traídos a Chile y descansan en su patria, cumpliendo su expresa voluntad ${ }^{2}$.

\section{Referencias}

1.- Jiménez de la Jara J. Abraham Horwitz (1910-2000). Padre de la Salud Pública Panamericana. Rev Méd Chile 2003; 131: 919-34.

2.- Kraljeviæ O. R. Profesor Dr. Abraham
Horwitz Barak (1910-2000). Rev Méd Chile 2001; 129: 456-60.

3.- Horwitz A B. Infección meningocóccica en Chile. Impta. Stanley. Santiago de Chile. 1942. p.11.

4.- Restrepo H. Obituario del doctor Abraham
Horwitz. Rev Fac Salud Pública 2000; 18: 159-60.

5.- Premio Abraham Horwitz al liderazgo en la Salud Interamericana. http://www.paho.org/ spanisch/PAHEF/hor. Correo Electrónico: info@pahef.org 